\title{
Rainfall prediction using Artificial Neural Network in the South Pacific region
}

\author{
Ashneel Chand \\ College of Science, Technology and Environment \\ The University of the South Pacific \\ Suva, Fiji \\ ashneel.chand@usp.ac.fj
}

\author{
Ravneil Nand \\ School of Computing, Information and Mathematical Sciences \\ The University of the South Pacific \\ Suva, Fiji \\ nand_ra@usp.ac.fj
}

\begin{abstract}
Rainfall prediction is one of the most important and at the same time challenging task. Meteorologists can predict weather patterns such as rainfall based on atmospheric parameters such as Humidity, Temperature, etc. This paper presents research on rainfall prediction based on historical dataset through neural network by training a network and testing it. Mean squared error (MSE) is used to generalize the performance of the model. Three different dataset, training algorithm and hidden layer setting is used for prediction. The results obtained reveals that ideally all three training algorithm is producing good results as MSE is closer to zero. Undoubtedly, neural network proves to be most appropriate technique for forecasting various weather phenomena such as rainfall. It can be further alluded that Bayesian Regularization tends to give lower MSE values compare to the other two training algorithms.
\end{abstract}

Keywords-Neural Network, prediction, rainfall, backpropagation, mean square error

\section{INTRODUCTION}

The chaotic and dynamic nature of weather makes weather forecasting a thought-provoking. Various numerical models have been developed and applied for this purpose, however usually they do not provide accurate predictions. Hence, there is a need to develop more precise models that could make better forecasting. Neural networks $(\mathrm{NN})$ are one of the most powerful artificial intelligence methods that are used for nonlinear modeling and especially for weather forecasting. It has the ability to learn relationship between complex input/output irrespective of linear and nonlinear relationships between the variables. Many researchers [1] [2] [3] [4] [5] [6] have applied different types of neural networks such as multilayered perceptron (MLP) or radial basis function (RBF), backpropagation network (BPN) for predicting the weather.

Temperature plays a key role on daily livestock and agriculture. This reason has led researchers to forecast the temperature. Even though forecasting of weather will not stop natural occurring disasters, it can provide means to many ways for planning natural calamities. The perception of temperature has advanced from the common concept of degree of hotness and coldness. The effect of temperature expresses itself through flooding and droughts. This has huge impact on soil, plats and living organism. A sudden change in weather pattern and its extreme condition account for about $3 / 4^{\text {th }}$ of all annual losses in farm production [7].

As per authors in [8], accurate forecast can done if meteorologist have gathered data from past and understands underlying principles occurring in the atmosphere that produces the current weather at a particular location, which can be then compared with the historical data. Then they stated that the forecast is be done by making observations of the atmosphere, which includes mean sea level, temperature, atmospheric pressure, wind direction and speed, humidity, cloud cover, precipitation, rainfall, etc. A good forecasting can be done by observing changes which takes place to these parameters over time and linking the changing patterns with historical patterns, a good forecasting is possible.

While there has been much deliberation done on climate change, the globe has witnessed numerous extreme weather condition such as tropical cyclones, flooding's, droughts, heat waves and cold in the last few decades. The climate change tends to be the biggest threat of the humankind. Hence, to meet the wide array of needs, several model have been developed for marking its prediction. Therefore, this makes rainfall very critical and widely measured variables across the globe. The variables defining weather conditions such temperature (maximum or minimum), relative humidity, rainfall differ always with time, forming time series of each parameter and can be used to develop a forecasting model either statistically or using some other means like artificial neural networks [9]. ANN's imitate the parallel distributed processing of the brain. Artificial neural networks are computationally robust as it has the ability to learn and generalize from examples to produce meaningful solutions to problems even when input data contain errors or are incomplete. An application of ANNs in rainfall forecasting is that it can be designed to operate in realtime.

Due to the diverse impacts of climate change, there is a huge interest in zero coal burning in coming years. Which means that many countries will opt for clean energy such as solar, wind, hydro, etc. Fiji's clean energy largely depends on the hydropower generation [10]; hence, it will be interesting to see how rainfall varies over the period for hydropower generation. Markedly, weather parameter such as rainfall are of great interest as its implications is directly related to everyday life.

The major objective of this papers is to test and train a neural network that has the ability to forecast the individual weather components such maximum and minimum temperature, rainfall, wind speed, relative humidity using historical weather data. Our main focus is to accurately predict the daily rainfall using Artificial Neural Network. This model can also be used to forecast other meteorological parameter's in the similar fashion. A total of three stations have been used in this study.

The paper is organized as follows. Section II is on literature review while section III is on model architecture. Section IV and V are on methodology and results respectively. 
Lastly, Section VI is on discussion while Section VII is on Conclusion and future recommendations.

\section{LITERATURE REVIEW}

This section opts to focus on the related work that has been done in rainfall forecasting using artificial neural network. Given the fact that the current world climate change is occurring at unprecedented rate, accurate rainfall forecasting is vital. There has been several works done with different artificial neural networks (ANN) and the model are tested. Due to the dynamics of the atmospheric processes, rainfall is highly nonlinear. Authors in [11] have developed and compared three types of ANN's suitable for rainfall prediction. This included multilyer feedforead neural netwrok, Elamn partial recurrent neural network and time delay network. They have stated that artificial neural network has proven to be a powerful mathematical model that excels at function approximation and pattern recognition. According to the authors in [12], they have indicated that ANN is a robust tool for the study of the medium and long-term climatic variability. A major advancement was achieved by [13], who expanded the applicability of ANNs to nonlinear systems and this development formed the basis of many ANNs used today [14]. Dynamic neural networks, which include tapped delay lines are used for nonlinear filtering and prediction [15]. Simulation and prediction of nonlinear data such as rainfall are demanding; therefore, considerable attention has been given to the development of sophisticated techniques for exploring this kind of data sets. One such class of techniques is artificial neural networks (ANNs). Researchers in [16], have tested the performance of the neural network for making prediction of daily precipitation using multiple sources. 30 years of daily precipitation, data (1970 -1999) from ten nearby weather stations was used in training and testing of the models. Daily precipitation data from 1970 to 1990 were used to train the networks while the remaining daily precipitation data were used to test the effectiveness of the models. The models had the ability to forecast the daily precipitation occurrence with an accuracy of $79 \pm 3 \%$ and fuzzy classification produced a higher accuracy in forecasting trace precipitation than other categories.

Based on relative humidity, dew point and pressure in India, [4] have used backpropagation neural network modeling for predicting the rainfall. Backpropagation or propagation of error, is a common means of educating artificial neural networks how to perform a task. $99.79 \%$ of the accuracy was achieved in the training of the model while $94.28 \%$ during testing phase, which lead to a conclusion that by using this method for prediction, rainfall amount can be predicated in the region by using attributes like humidity, dew point and pressure. While the dynamics of the rainfall is highly nonlinear and rainfall is not well understood, artificial neural network is the good choice worth trying to investigate the relationship between meteorological parameter's and rainfall. A real world case study was observed in Chennai by [3]. The authors have used 32 years of monthly mean of wind speed, mean temperature, relative humidity aerosol values in the area were used to develop the ANN model. In order to forecast rainfall in Chennai city, backpropagation network, a data technique based on the working principle of biological neurons are applied in this study. More significantly [3] had presented an application of Back Propagation Neural (BPN) Network for weather prediction. Their proposed idea is tested using the real time dataset. The results are compared with practical working of meteorological department and these results confirm that the real time processing of weather data indicate that the backpropagation network based weather forecast have shown improvement not only over guidance forecasts from numerical models, but over official local weather service forecasts as well.

As per authors in [2] they have used backpropagation neural network in their research for making mean monthly rainfall forecasting. The model did performed well both in the training and independent periods however they have suggested that more input parameters are required in accurate prediction of peak values of rainfall. Temperature is one the thriving factor of forecasting rainfall. Authors in [6] have tested artificial neural network in forecasting minimum temperature, whereby they have used multi-layer perceptron architecture to model the forecasting system and backpropagation for training. The results show that an appropriate accuracy can be achieved using this model. Interestingly, this approach has the high potential to determine the values of other parameters like maximum relative humidity, minimum relative humidity, maximum temperature, etc. It was found that minimum temperature could be predicted with reasonable accuracy using artificial neural network model. Given that the weather data is nonlinear and follows a very irregular trend, artificial neural network (ANN) has evolved out to be a better technique to bring out the structural relationship between the various entities. It is known that neural network training is better with larger dataset [1]. Researchers in [1] have also applied ANN prediction for rainfall over Udipi district of Karnataka. Their research showed that backpropagation was better than the layer recurrent and cascaded backpropagation.

A few surveys exist on rainfall forecasting. Different techniques like Multi-Layer Perceptron Neural Network (MLPNN), Back Propagation Algorithm (BP A), Radial Basis Function Network (RBFN), SOM (Self Organization Map) and SVM (Support Vector Machine) survey has been done by [5]. From the survey, the authors concluded that most of the researchers used back propagation algorithm for rainfall prediction. Moving on, it is observed that the forecasting accuracy of artificial neural network can be improved by considering other meteorological parameters (evaporation, mean temperature, humidity, and soil temperature) as inputs. Weather temperature prediction based on ensembles of neural network has been done by [17]. In this, the researchers proposed the model for temperature prediction that composed of four different stages. It was notable that, while an ensemble of neural networks had considered in the proposed model, the model itself was also modular, and the learning process is modular via a feature selection task at the first stage. To reduce the redundancy caused by considering ensemble of networks, and decrease the complexity, they proposed to calculate the correlations between the output of each network and the actual result, based on a mutual information approach. Suggestions has been made by [18] that there is a need to include a comparison of a few ANN methods and the optimization process in order to obtain more accurate prediction results.

A careful review of the literature depicts that the artificial neural network technique is effective and has been extensively used for weather forecasting given its nonlinear pattern. 


\section{MODEL ARCHITECTURE}

Authors in [7] has highlighted that neural network is a very strong data modeling technique that has the ability to represent complex relationship between input and output. Neural network seems to work analogues with human brain. It obtains information for learning pattern recognition, identification, etc. The information is then stored in the interconnected neurons in terms of its weight which then tends to make projections using the input data. The nature of the weather data is such that artificial neural network has become the most attractive in solving nonlinear problems. Neural network has the capability to characterize both linear and nonlinear relationship directly from the data [17]. The literature review shows that many researchers has utilized neural networks such as multi-layer perceptron (MLP), radial based function (RBF), backpropagation (BP) in weather forecasting. Hence, neural network tends to be one of the most influential artificial intelligence techniques that are used for nonlinear modeling for example rainfall prediction. The proposed model is shown in Fig. 1.

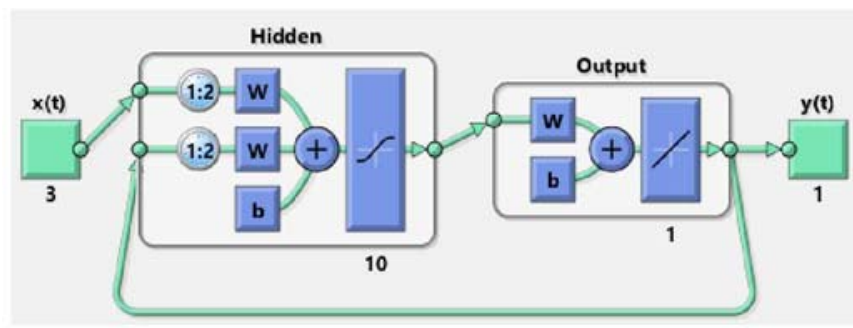

Fig. 1. Proposed neural network model having 3 input.

Neural networks has the ability to learn and extract pattern from the data and therefore to achieve this, the network needs to be trained. Large data set is vital during training as this allows the neural network to learn and recognize patterns. $70 \%$ of the data is used for training while $30 \%$ of data has been used for validation and testing. The neural network consists of three layers, namely input, hidden and output layers as shown in Fig. 2. This input and output is in the form of nodes representing the predictor and predicted variables respectively. The input layer contains independent variables that is connected to hidden layers for processing. The hidden layer contains of activation functions, which calculates the weights of the variables in order to explore the effects of predictors upon the target variables. The output layer is the end part of the network where results are presented with small error. The input variables in research are maximum temperature, minimum temperature, relative humidity, mean sea level pressure and wind speed. The neural network performance is better when increasing number of samples and increasing number of neuron [19]. The very step is to train the network. The training phase is very vital. It is designed to optimize the weights so that the mean-squared error of the output is minimized. The network is trained until minimum error is noted.

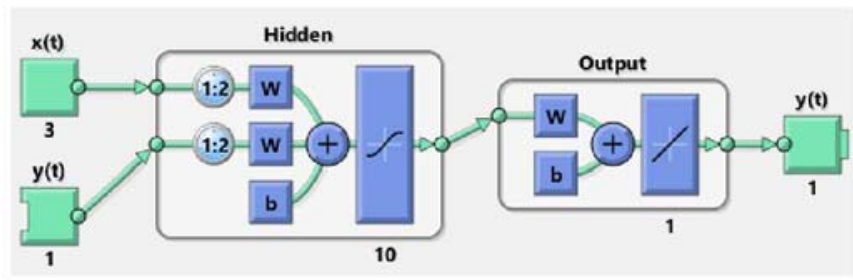

Fig. 2. Proposed model layer archituture.
For learning purpose, some regularization techniques has been used to train the neural network algorithm so that minimum error is achieved. It permits the neural network to be smooth and less likely to over fit to training patterns. There has been many different regularization methods developed to overcome the overfitting problem. LevenbergMarquardt and Bayesian Regularization are most widely techniques used because of their respective advantage [20]. In this paper we will use Lavenberg-Marquardt, Bayesian Regularization and Scaled Conjugate Gradient backpropagation techniques.

\section{METHODOLOGY}

This research uses the historical weather data form 2006 2018 recorded from three different stations (namely Nadi, Laucala and Lautoka) in Viti Levu. Nadi and Laucala has total of 4748 data while Lautoka had total of 4400 data. Sufficient data is required so that Artificial Neural Network model can actually predict rainfall after adequate training. Hence, daily rainfall, daily minimum and maximum temperature data for past 13 years was obtained from Fiji Meteorological Services. Relative humidity, mean sea level pressure and wind speed data is recorded eight times in a day at every 3-hour intervals. These set of data was also obtained from Fiji Meteorological services. For relative humidity, mean sea level pressure and wind speed, 9 am data was used for the same period as this set of data was most complete compared to other times measured within a day. Very few stations had 9 am data missing, therefore $3 \mathrm{pm}$ data had been used instead as this was the second most complete data set when compared to other times. One of the challenges in the meteorological data is the incomplete data. For this reason, missing values were given careful attention. Stations that has huge missing data has been omitted. Markedly, data is cleaned by filling in the missing values with mean values [4] [21]. The average values of the readings day before and after of the missing value has been calculated using (1).

$$
\bar{x}=\frac{x_{i}+x_{i+2}}{2}
$$

Where $x_{i}$ is day before and $x_{i+2}$ is the day after missing value.

In our data where consecutive missing values were noticed, the average value of the month has been calculated using (2). There was no more than 7 days of consecutive missing value for a particular month and station.

$$
\bar{x}=\frac{\sum_{i=1}^{n} x_{i}}{n}
$$

Where $\sum_{i=1}^{n} x_{i}=x_{1}+x_{2}+x_{3}+\ldots . x_{n}$ and $n$ is the number of terms.

Moving on, input and the output data has been normalized as they are of different units. This process reduces the data redundancy and improves data integrity. First, the mean of all the data was computed separately. Then the standard deviation for each attributes were calculated individually. After the mean and standard deviation, SD, was obtained, the values of each attributes was normalized using (3). 


$$
\text { Normalized value }=\frac{(x-\bar{x})}{S D}
$$

Authors in [1] has also used the same technique to normalize data. Outliers in weather data can arise due data entry or malfunctions of the measuring instruments. Given the fact that the climate change is occurring at unpresented rate, we assume these outliers could be the extreme events. Therefore, the impacts of climate change includes extreme occurrence of flooding and drought and the damage sustain by such event is colossal. These values could be very low or high during extreme evets. The data would have also reduced dramatically if outliers were given attention and removed.

TABLE I. METEOROLOGICAL DATA AND THEIR NORMALIZATION

\begin{tabular}{|c|c|c|c|}
\hline Signal & Kinds of data & Value range & $\begin{array}{c}\text { Normalized } \\
\text { Data }\end{array}$ \\
\hline \multirow{5}{*}{ Input } & $\begin{array}{l}\text { Maximum } \\
\text { Temperature }\end{array}$ & $21.4-36.5^{\circ} \mathrm{C}$ & \multirow{5}{*}{$\begin{array}{l}\text { Distribution } \\
\text { characterized } \\
\text { by mean and } \\
\text { standard } \\
\text { deviation }\end{array}$} \\
\hline & $\begin{array}{l}\text { Minimum } \\
\text { Temperature }\end{array}$ & $13-27.5^{\circ} \mathrm{C}$ & \\
\hline & $\begin{array}{l}\text { Relative } \\
\text { Humidity }\end{array}$ & $0-100 \%$ & \\
\hline & $\begin{array}{l}\text { Mean Sea Level } \\
\text { Pressure }\end{array}$ & $0-1022 \mathrm{hPa}$ & \\
\hline & Winds Speed & $0-13.4 \mathrm{~ms}^{-1}$ & \\
\hline Output & Rainfall & - & $0-1$ \\
\hline
\end{tabular}

The literature review shows that more inputs to Artificial Neural Network with sufficient data give precise forecasting. We have used 3 to 5 different rainfall attributes such as maximum and minimum temperature, relative humidity, wind speed and mean sea level pressure for marking predictions. Due to the availability and completeness of the data for each stations, inputs fed into the model was also varied.

The data received for each of the stations includes, Nadi had the all 5 attributes stated above while Nausori and Laucala had 4 attributes which included maximum and minimum temperature, relative humidity and mean sea level pressure. While other stations such as Navua, Lautoka, Monosavu, Nacocolevu, and Penang had 3 attributes which were maximum and minimum temperature and relative humidity. Therefore, three stations were picked which comprised of Nadi, Laucala and Lautoka where input attributes varied from 3 to 5 entries. These will also give us a better understanding of how accurate forecasting gets with different attributes and number of inputs.

When a network has been developed for a specific purpose, inputs and corresponding targets are used to train a network unit it learns to associate a particular input with a reasonable output [5]. As mentioned by authors in [19] , Neural Network training is better with larger dataset. Hence, we have used $70 \%$ of data from 4758 (Nadi dataset) and 4400 (Laucala and Lautoka dataset) samples for training purpose while $30 \%$ is used for making validation and testing. The 4748 and 4400 samples of daily data form 2006 to 2018 was possible through data cleaning and pre-processing using excel and MATLAB. Inputs were normalized to allow better generalization of results while output was transformed to 0 or 1 indicating rainfall occurrence or not in binary.
For learning purpose we have used Levenberg-Marquardt, Bayesian Regularization and Seated Conjugate Gradient. These backpropagation algorithms are used for training the network. Various network structures has been applied in order to achieve the best structure of the network keeping in mind the hidden neuron. The Mean Square Error (MSE) determine the performance of the neural network. The algorithm was run 20 times where mean results of the runs are reported. The iteration was set to 1000 as in literature.

\section{RESULTS}

This section reports on the experimental results. Three stations namely Nadi, Laucala and Lautoka are discussed here.

Nadi has five attributes while Laucala has 4 and Lautoka has 3 attributes as mentioned earlier. Tables II - IV show results obtained for the three stations. Train, Valuation and Test MSE with Best run MSE is reported. Best results reported are in bold.

Table II shows performance of the model on Nadi dataset where results are reported for 3 training algorithm on 3 different sets on hidden neuron setting. It can be seen that for two hidden neuron setting, Best results are obtained with Bayesian algorithm while Lavenberg-marquardt algorithm had closer result to Bayesian. It had best result in hidden neuron 5. For all the settings, all three methods have the results close to each other.

TABLE II. RESULTS ON NADI DATASET

\begin{tabular}{|c|l|c|c|c|c|}
\hline \multirow{2}{*}{$\begin{array}{c}\text { No. of } \\
\text { Hidden } \\
\text { Neuron }\end{array}$} & \multicolumn{5}{|c|}{ Merformance } \\
\cline { 2 - 6 } & $\begin{array}{c}\text { Train } \\
\text { MSE }\end{array}$ & $\begin{array}{c}\text { Val } \\
\text { MSE }\end{array}$ & $\begin{array}{c}\text { Test } \\
\text { MSE }\end{array}$ & Best \\
\hline \multirow{2}{*}{1} & $\begin{array}{l}\text { Levenberg- } \\
\text { Marquardt } \\
\text { backpropagation }\end{array}$ & 0.1872 & 0.1882 & 0.1895 & $\mathbf{0 . 1 8 2 7}$ \\
\cline { 2 - 6 } & $\begin{array}{l}\text { Bayesian } \\
\text { Regularization } \\
\text { backpropagation }\end{array}$ & $\mathbf{0 . 1 8 6 1}$ & - & $\mathbf{0 . 1 8 9 5}$ & 0.1843 \\
\cline { 2 - 6 } & $\begin{array}{l}\text { Scaled conjugate } \\
\text { gradient } \\
\text { backpropagation }\end{array}$ & 0.1894 & $\mathbf{0 . 1 8 7 5}$ & 0.1905 & 0.1843 \\
\hline \multirow{5}{*}{5} & $\begin{array}{l}\text { Levenberg- } \\
\text { Marquardt } \\
\text { backpropagation }\end{array}$ & $\mathbf{0 . 1 8 4 2}$ & 0.1901 & 0.1921 & $\mathbf{0 . 1 7 9 9}$ \\
\cline { 2 - 6 } & $\begin{array}{l}\text { Bayesian } \\
\text { Regularization } \\
\text { backpropagation }\end{array}$ & 0.1867 & - & $\mathbf{0 . 1 8 9 5}$ & 0.1813 \\
\cline { 2 - 6 } & $\begin{array}{l}\text { Scaled conjugate } \\
\text { gradient } \\
\text { backpropagation }\end{array}$ & 0.1872 & $\mathbf{0 . 1 8 7 4}$ & 0.1933 & 0.1826 \\
\hline \multirow{5}{*}{10} & $\begin{array}{l}\text { Levenberg- } \\
\text { Marquardt } \\
\text { backpropagation }\end{array}$ & 0.1840 & $\mathbf{0 . 1 8 5 8}$ & 0.1921 & 0.1807 \\
\cline { 2 - 6 } & $\begin{array}{l}\text { Bayesian } \\
\text { Regularization } \\
\text { backpropagation }\end{array}$ & $\mathbf{0 . 1 8 2 8}$ & - & $\mathbf{0 . 1 8 7 3}$ & $\mathbf{0 . 1 7 7 9}$ \\
\cline { 2 - 6 } & $\begin{array}{l}\text { Scaled conjugate } \\
\text { gradient } \\
\text { backpropagation }\end{array}$ & 0.1870 & 0.1895 & 0.1895 & 0.1834 \\
\hline
\end{tabular}

Table III shows performance of the model on Laucala dataset where results are reported for the 3 training algorithm based on 3 hidden neuron settings. It can be seen as in Nadi dataset that for two hidden neuron setting, better results are obtained 
with Bayesian algorithm from Lavenberg and scaled conjugate methods. Levenberg method has good performance on 10 hidden neuron setting.

TABLE III. RESULTS ON LAUCALA DATASET

\begin{tabular}{|c|l|c|c|c|c|}
\hline $\begin{array}{c}\text { No. of } \\
\text { Hidden } \\
\text { Neuron }\end{array}$ & \multicolumn{5}{|c|}{ Performance } \\
\cline { 2 - 6 } & Method & $\begin{array}{c}\text { Train } \\
\text { MSE }\end{array}$ & $\begin{array}{c}\text { Val } \\
\text { MSE }\end{array}$ & $\begin{array}{c}\text { Test } \\
\text { MSE }\end{array}$ & Best \\
\hline \multirow{5}{*}{1} & $\begin{array}{l}\text { Levenberg- } \\
\text { Marquardt }\end{array}$ & 0.1966 & $\mathbf{0 . 1 9 8 4}$ & 0.2030 & 0.1940 \\
\cline { 2 - 6 } & $\begin{array}{l}\text { Bayesian } \\
\text { Regularization }\end{array}$ & $\mathbf{0 . 1 9 6 5}$ & - & $\mathbf{0 . 1 9 9 1}$ & $\mathbf{0 . 1 9 3 8}$ \\
\cline { 2 - 6 } & $\begin{array}{l}\text { Scaled conjugate } \\
\text { gradient }\end{array}$ & 0.1990 & 0.1986 & 0.1999 & 0.1940 \\
\hline \multirow{5}{*}{5} & $\begin{array}{l}\text { Levenberg- } \\
\text { Marquardt }\end{array}$ & $\mathbf{0 . 1 9 5 1}$ & $\mathbf{0 . 1 9 6 5}$ & 0.2010 & 0.1915 \\
\cline { 2 - 6 } & $\begin{array}{l}\text { Bayesian } \\
\text { Regularization }\end{array}$ & 0.1956 & - & $\mathbf{0 . 1 9 8 9}$ & $\mathbf{0 . 1 9 0 9}$ \\
\cline { 2 - 6 } & $\begin{array}{l}\text { Scaled conjugate } \\
\text { gradient }\end{array}$ & 0.1985 & 0.1974 & 0.2014 & 0.1940 \\
\hline \multirow{3}{*}{10} & $\begin{array}{l}\text { Levenberg- } \\
\text { Marquardt }\end{array}$ & $\mathbf{0 . 1 9 5 1}$ & 0.2018 & $\mathbf{1 . 9 9 9}$ & $\mathbf{0 . 1 9 2 1}$ \\
\cline { 2 - 6 } & $\begin{array}{l}\text { Bayesian } \\
\text { Regularization }\end{array}$ & 0.1961 & - & 0.2000 & 0.1943 \\
\cline { 2 - 6 } & $\begin{array}{l}\text { Scaled conjugate } \\
\text { gradient }\end{array}$ & 0.1983 & 0.1985 & 0.2004 & 0.1951 \\
\hline
\end{tabular}

Table IV shows performance of the model on Lautoka dataset. It can be seen as in Nadi and Laucala dataset that for at least two hidden neuron setting, better results are obtained with Bayesian algorithm then the other two. Levenberg method has slighted better performed than scaled conjugate where it has performed better than Bayesian on 1 hidden neuron.

TABLE IV. RESULTS ON LAUTOKA DATASET

\begin{tabular}{|c|c|c|c|c|c|}
\hline \multirow{2}{*}{$\begin{array}{l}\text { No. of } \\
\text { Hidden } \\
\text { Neuron }\end{array}$} & \multicolumn{5}{|c|}{ Performance } \\
\hline & Method & $\begin{array}{l}\text { Train } \\
\text { MSE }\end{array}$ & $\begin{array}{c}\text { Val } \\
\text { MSE }\end{array}$ & $\begin{array}{c}\text { Test } \\
\text { MSE }\end{array}$ & Best \\
\hline \multirow{3}{*}{1} & $\begin{array}{l}\text { Levenberg- } \\
\text { Marquardt } \\
\text { backpropagation }\end{array}$ & 0.1804 & 0.1835 & 0.1832 & 0.1775 \\
\hline & $\begin{array}{l}\text { Bayesian } \\
\text { Regularization } \\
\text { backpropagation }\end{array}$ & 0.1799 & - & 0.1855 & 0.1780 \\
\hline & $\begin{array}{l}\text { Scaled conjugate } \\
\text { gradient } \\
\text { backpropagation }\end{array}$ & 0.1817 & 0.1807 & 0.1836 & 0.1781 \\
\hline \multirow{3}{*}{5} & $\begin{array}{l}\text { Levenberg- } \\
\text { Marquardt } \\
\text { backpropagation }\end{array}$ & 0.1792 & 0.1793 & 0.1820 & 0.1751 \\
\hline & $\begin{array}{l}\text { Bayesian } \\
\text { Regularization } \\
\text { backpropagation }\end{array}$ & 0.1778 & - & 0.1805 & 0.1747 \\
\hline & $\begin{array}{l}\text { Scaled conjugate } \\
\text { gradient } \\
\text { backpropagation }\end{array}$ & 0.1825 & 0.1775 & 0.1843 & 0.1790 \\
\hline \multirow{3}{*}{10} & $\begin{array}{l}\text { Levenberg- } \\
\text { Marquardt } \\
\text { backpropagation }\end{array}$ & 0.1786 & 0.1811 & 0.1834 & 0.1749 \\
\hline & $\begin{array}{l}\text { Bayesian } \\
\text { Regularization } \\
\text { backpropagation }\end{array}$ & 0.1763 & - & 0.1865 & 0.1729 \\
\hline & $\begin{array}{l}\text { Scaled conjugate } \\
\text { gradient } \\
\text { backpropagation }\end{array}$ & 0.1808 & 0.1815 & 0.1818 & 0.1766 \\
\hline
\end{tabular}

Fig. 3 to Fig. 5 shows typical MSE convergence for Nadi, Laucala and Lautoka stations. Fig. 3 is based on LevenbergMarquardt backpropagation algorithm, Fig. 4 is based on
Bayesian while Fig. 5 is based on Scaled conjugate gradient backpropagation training algorithm.

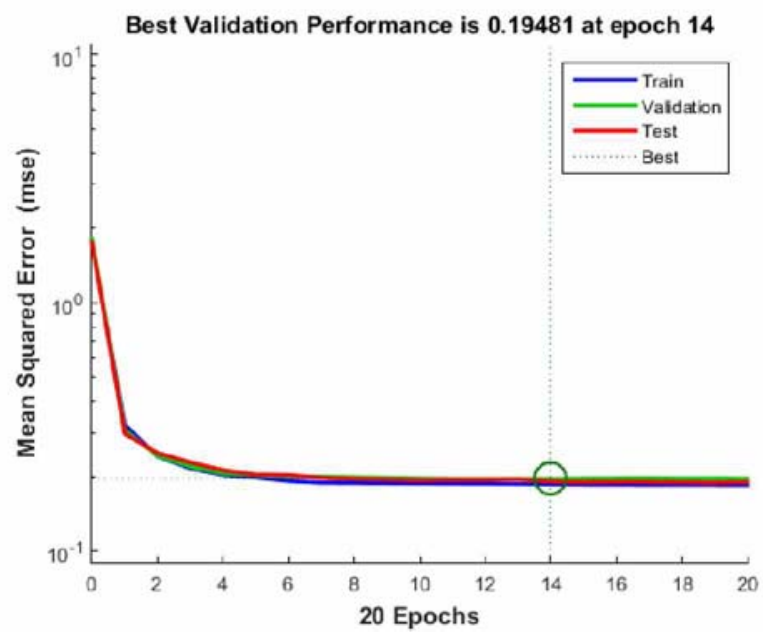

Fig. 3. Typical evaluation of Training, Validation \& Testing Performance for Nadi for 1 Hidden Neuron

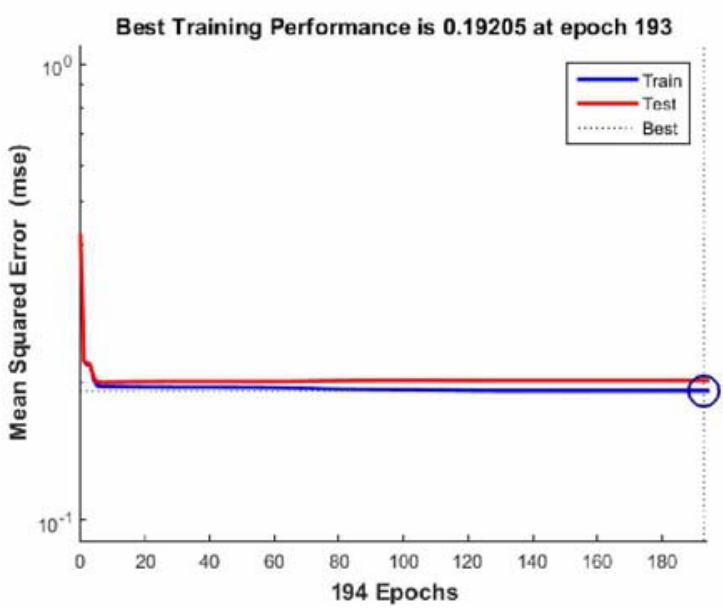

Fig. 4. Typical evaluation of Training \& Testing Performance for Laucala for 5 hidden neurons

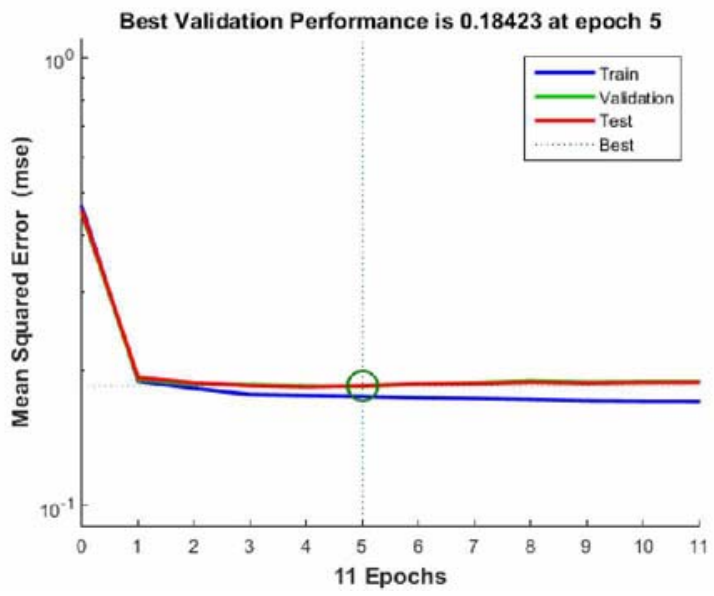

Fig. 5. Typical evaluation of Training, Validation \& Testing Performance for Lautoka for 10 Hidden Neurons

Fig. 6 shows best fit for Nadi dataset. The figure displays the network outputs with respect to targets for training, validation, and test sets. 

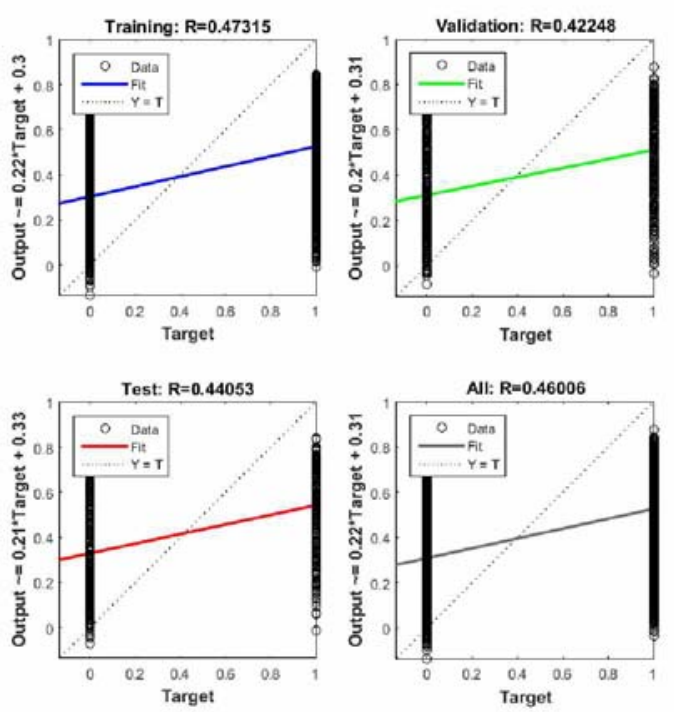

Fig. 6. Typical Regression plot of Training, Validation \& Testing Performance for Nadi dataset.

Fig. 7 shows error histogram for Nadi dataset while Fig. 8 shows the correlation of error at time $t$ for Nadi over varying time lags.

Fig. 9 shows input and error correlation for Nadi dataset while Fig. 10 shows training state for Lautoka dataset.

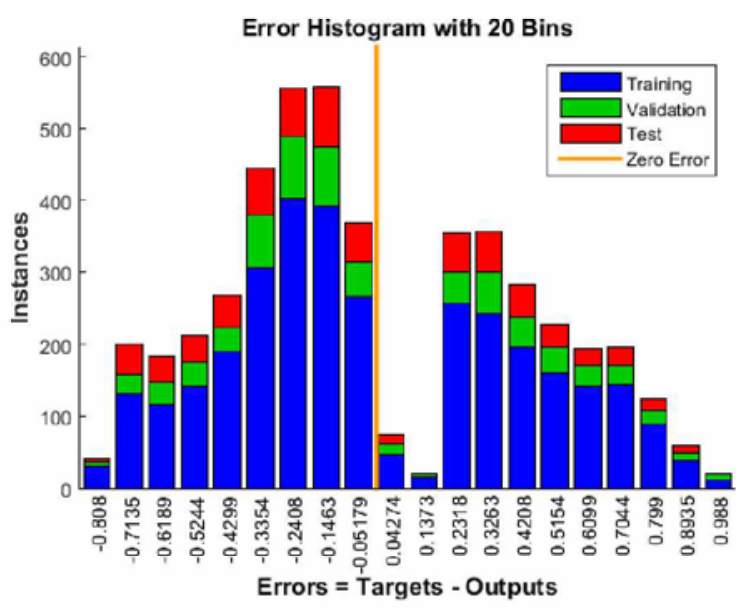

Fig. 7. Typical Error Histogram for Nadi dataset.

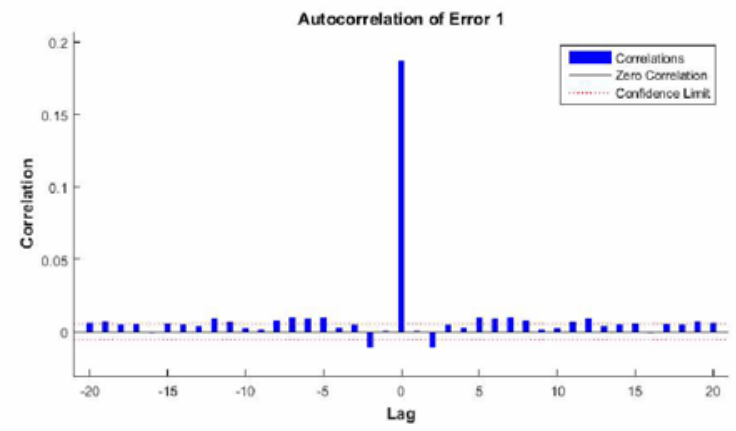

Fig. 8. Typical autocorrelation of Error for Nadi dataset.

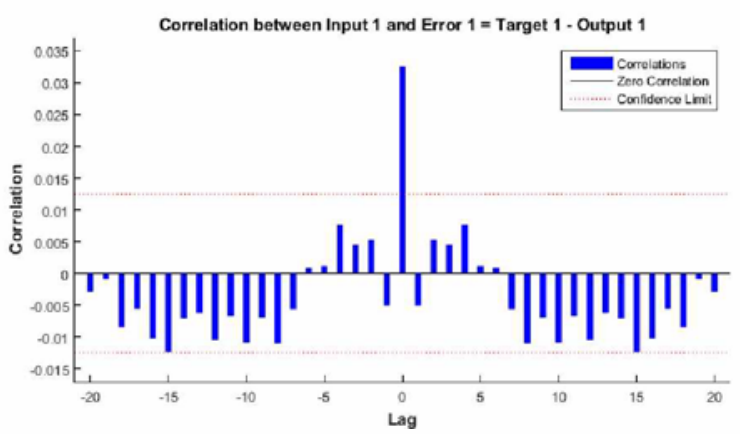

Fig. 9. Typical input and error correlation for Nadi dataset.
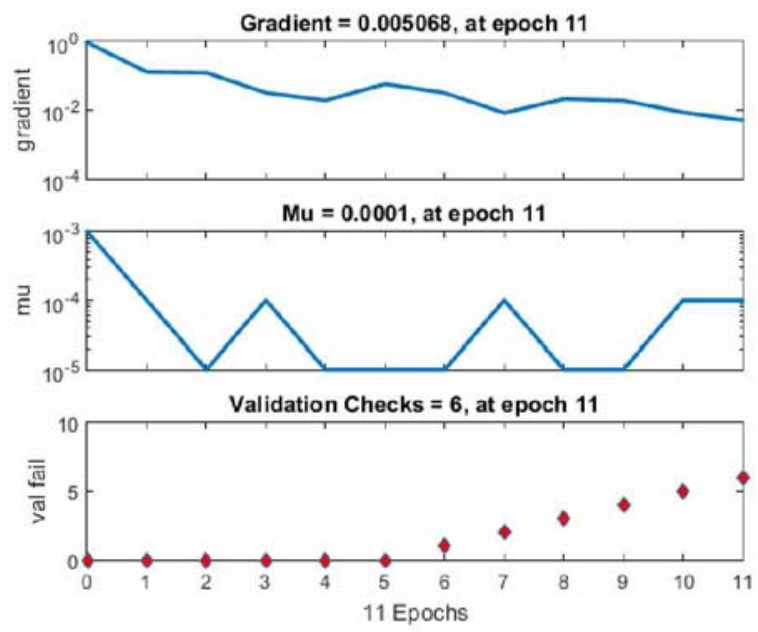

Fig. 10. Typical training state for Lautoka dataset.

\section{DISCUSSION}

This section reports on the discussion of the results obtained.

It can be seen from the results in Tables II to IV that, Levenberg-Marquardt and Bayesian training function are suitable for this type of dataset. These two methods use Jacobian calculations, which has given better performance than gradient based method. Results on Nadi dataset is given in table II. It shows that for 1 and 10 number of hidden neuron, Bayesian regularization gives 0.1861 and 0.1828 values of MSE during training phase while it is 0.1842 for Lavenberg-Marquardt for 5 number of hidden neurons for same dataset. The table further shows that Best MSE tend to be same as mentioned above. In addition to this, something similar can be noticed from tables II and IV.

As for the Fig. 3 and Fig. 5, the training stopped when the validation error increased. Fig. 4 shows that the Bayesian algorithm used does not have validation, that's why the iteration stopped on 194. The reason for that is for training to continue until an optimal combination of errors and weights is found. The figures clearly show that there is not much of a difference between the predicted and actual output. Fig.6 displays the network outputs with respect to targets for training, validation, and test sets. The $\mathrm{R}$ value indicate a positive relationship. The outlier is visible on test plot. 
In Fig. 7, the blue bars represent training data, the green bars represent validation data, and the red bars represent testing data. The histogram gives an indication of outliers, which are data points where the fit is significantly worse than the majority of data. In this case, it can be seen that at most errors fall between -0.8 and 0.9 . There are two outliers observed. These outliers are also visible on the testing regression plot. It is a good idea to check the outliers to determine if the data is different than the rest of the data set. If the outliers are valid data points, but are unlike the rest of the data, then the network is generalizing for these points.

Fig. 8 and Fig 9, show error correlation. First is the correlation of error at time $t, e(t)$ with errors over varying lags, e $(\mathrm{t}+\mathrm{lag})$. The center line shows the mean squared error. Second graph shows error in terms of inputs with varying time leg. The bars indicate that the most of the errors follow in between the confidence limits. Fig. 10 shows how the gradient method solves the problem with momentum constant (mu).

\section{CONCLUSION}

Rainfall forecasting plays a significant role and accurate prediction of it can be substantially decrease the impact cost pertaining issues related to rainfall. Hence this study concentrates on capabilities of neural network using three different training techniques in prediction of weather phenomenon such as rainfall. It can be said that Bayesian regularization backpropagation tends to give the smallest MSE values compared to Lavenberg-Marquardt and scaled conjugate gradient. The results also shows that LavenbergMarquardt give better results than scaled conjugate gradient. Ideally all the three gave lower MSE values. Typical Regression plot of Training, Validation \& Testing Performance also give a very good results which means that the rainfall data training results has a good prediction accuracy by using the equation Output $=0.22 *$ Target +0.31 . The performance of the model is defined in terms of data modeling, handling of missing values from the data set and mean square error during the training and testing phase. In this study the number of inputs was also studied. It can be further alluded that the attributes used are accurate enough to predict weather patterns.

The proposed methodology currently functions well for rainfall prediction; the same method can be used to forecast Temperature, Humidity, Wind Speed, etc.

\section{REFERENCES}

[1] K. Abhishek, A. Kumar, R. Ranjan and S. Kumar, "A rainfall prediction model using artificial neural network," in 2012 IEEE Control and System Graduate Research Colloquium, 2012.

[2] G. Geetha and R. S. Selvaraj, "Prediction of monthly rainfall in Chennai using back propagation neural network model," International Journal of Engineering Science and Technology, vol. 3, no. 1, 2011.

[3] S. S. Baboo and I. K. Shereef, "An efficient weather forecasting system using artificial neural network," International journal of environmental science and development, vol. 1, no. 4, p. 321, 2010.

[4] E. Vamsidhar, K. Varma, P. S. Rao and R. Satapati, "Prediction of rainfall using backpropagation neural network model,"
International Journal on Computer Science and Engineering, vol. 2, no. 4, pp. 1119-1121, 2010.

[5] D. R. Nayak, A. Mahapatra and P. Mishra, "A survey on rainfal prediction using artificial neural network," International Journal of Computer Applications, vol. 72, no. 16, 2013

[6] A. Kaur and H. Singh, "Artificial neural network in forecasting minimum temperature," International Journal of Electronics \& Communication Technology, vol. 2, no. 3, pp. 101-105, 2011.

[7] H. Tyagi, S. Suran and V. Pattanaik, "Weather-Temperature Pattern Prediction and Anomaly Identification using Artificial Neural Network," International Journal of Computer Applications, vol. 975, p. 8887, 2016.

[8] A. Geetha and G. M. Nasira, "Artificial neural networks' application in weather forecasting-using RapidMiner," International Journal of Computational Intelligence and Informatics, vol. 4, no. 3, pp. 177-182, 2014.

[9] A. Saxena, N. Verma and K. C. Tripathi, "A review study of weather forecasting using artificial neural network approach," Int. J. Eng. Res. Technol, vol. 2, no. 11, pp. 2029-2036, 2013.

[10] M. Dornan and F. Jotzo, "Renewable technologies and risk mitigation in small island developing states: Fiji's electricity sector," Renewable and Sustainable Energy Reviews, vol. 48, pp. $35-48,2015$.

[11] K. C. Luk, J. E. Ball and A. Sharma, "An application of artificial neural networks for rainfall forecasting," Mathematical and Computer modelling, vol. 33, no. 6-7, pp. 683-693, 2001

[12] S. C. Michaelides, C. S. Pattichis and G. Kleovoulou, "Classification of rainfall variability by using artificial neural networks," International Journal of Climatology: A Journal of the Royal Meteorological Society, vol. 21, no. 11, pp. 14011414,2001

[13] P. Werbos, "Beyond Regression:" New Tools for Prediction and Analysis in the Behavioral Sciences," Ph. D. dissertation, Harvard University, 1974.

[14] B. v. Maanen, G. Coco, K. R. Bryan and B. G. Ruessink, "The use of artificial neural networks to analyze and predict alongshore sediment transport," Nonlinear Processes in Geophysics, vol. 17, no. 5, pp. 395-404, 2010.

[15] C. Wang, "Time series neural network systems in stock index forecasting," Computer Modelling \& New Technologies, vol. 19, no. 1, pp. 57-61, 2015.

[16] H. D. P. Weerasinghe, H. L. Premaratne and D. U. J. Sonnadara, "Performance of neural networks in forecasting daily precipitation using multiple sources," Journal of the National Science Foundation of Sri Lanka, vol. 38, no. 3, 2010

[17] A. Ahmadi, Z. Zargaran, A. Mohebi and F. Taghavi, "Hybrid model for weather forecasting using ensemble of neural networks and mutual information," in 2014 IEEE Geoscience and Remote Sensing Symposium, 2014.

[18] S. Hardwinarto and M. Aipassa, "Rainfall monthly prediction based on artificial neural network: A case study in Tenggarong Station, East Kalimantan-Indonesia," Procedia Computer Science, vol. 59, pp. 142-151, 2015.

[19] K. Abhishek, M. P. Singh, S. Ghosh and A. Anand, "Weather forecasting model using artificial neural network," Procedia Technology, vol. 4, pp. 311-318, 2012.

[20] O. Baghirli, Comparison of Lavenberg-Marquardt, scaled conjugate gradient and Bayesian regularization backpropagation algorithms for multistep ahead wind speed forecasting using multilayer perceptron feedforward neural network, 2015.

[21] P. Matzneller, F. Ventura, N. Gaspari and P. R. Pisa, "Analysis of climatic trends in data from the agrometeorological station of Bologna-Cadriano, Italy (1952-2007)," Climatic change, vol. 100, no. 3-4, pp. 717-731, 2010. 